\title{
Re-imagining Operatic “Objects”: Commentary on Neumann's Phenomena, Poiesis, and Performance Profiling: Temporal-Textual Emphasis and Creative Process Analysis in Turandot at the Metropolitan Opera
}

\author{
GEORGIA VOLIOTI [1] \\ University of Surrey, United Kingdom
}

\begin{abstract}
Objects come in all sorts of shapes, sizes and forms. The notion of musical works as objects, represented by their written scores, has proved to be effete and limiting to the study of music as diverse social-cultural practice and performed craft. The past two decades have witnessed considerable efforts to renew conceptual and methodological tools, and Neumann's study makes a valuable contribution to this effect. This commentary responds to some issues raised by Neumann's article in relation to the notion of musical "object". Specifically, I retrace the shift from a score-based to a process-oriented musicology geared towards performances, placing the concerns of contemporary opera studies within this broader disciplinary change. I consider some implications of technology in mediating new operatic objects for discourse. Finally, I reflect on some of the inherent dangers of objectifying performance in empirical analyses.
\end{abstract}

Submitted 2017 July 15; accepted 2017 July 21.

KEYWORDS: musical object, empirical performance analysis, opera, technological mediation

\section{RETHINKING THE MUSICAL OBJECT}

NEUMANN'S study makes a valuable contribution to scholarship at the intersection between empirical musicology and performance studies. In the opening section of his article, Neumann critically interrogates, albeit rather succinctly, the (mis)conception of musical works as "things" or "objects". Taking as his starting point Roland Barthes's apt quotation about the need to "change the musical object as it presents itself to discourse" (Barthes, 1990, p. 180), Neumann places emphasis on the operatic event, which as he defines is "an accumulation of musical phenomena and experiences", positing that performances and their sounded phenomena rather than scores ought to be the focus of our scholarly interest. Similar views have, of course, been variably expressed over the past twenty years by a far more extensive musicological discourse, pertaining to the ontology of the musical work, than Neumann has space to deal with. This inevitable omission, since Neumann's article focuses more on the specifics of empirical performance analysis, prompts me to retrace here some important landmarks of the discourse underpinning the shift to a performance-based musicology as a means of complementing Neumann's discussion and placing his empirical approach within broader disciplinary concerns.

The project of New Musicology in the 1990s sought to dismantle the autonomy invested in musical works and challenge hegemonic ideas reinforced by traditional score-based analysis and criticism that treated musical compositions as self-contained, unified, stable entities existing independent of any real context. Writings by eminent scholars, such as Susan McClary (1991), Lawrence Kramer (2002) and Richard Leppert (Leppert \& McClary, 1989), to name just a few, became paradigmatic of critical readings of musical works in terms of their historical and social context. Although clearly influenced by the cultural turn in the humanities, New Musicology had not been infiltrated by the performative turn, at least not extensively enough to shift the emphasis in the study of music from the realm of representational meaning to that of practice. Rethinking Music (Cook \& Everist, 1999) sought to critically reflect on the premises of a score-based musicology, the alleged failings or unfulfilled ambitions of New Musicology, and to re-evaluate the discipline's priorities at the turn of the twenty-first century. But curiously, as Nicholas Till astutely observes, there is no mention of the study of opera in this seminal compendium (Till, 2012a, pp. 4-5). I will return to some of the issues 
concerning an opera-specific analytical discourse later in my discussion. Despite opera's exclusion, various chapters in Rethinking Music, such as Nicholas Cook's 'Analysing Performance and Performing Analysis’ (Cook \& Everist, 1999, pp. 239-61), John Rink’s ‘Translating Musical Meaning: The Nineteenth-Century Performer as Narrator’ (Cook \& Everist, 1999, pp. 217-38) or José Bowen’s 'Finding the Music in Musicology: Performance History and Musical Works' (Cook \& Everist, 1999, pp. 424-51), as well as numerous publications that soon followed (e.g., Cook, 2001, 2003; Rink, 2002), reflect a concerted effort to move towards a process-oriented musicology; one predicated on practices and specifically performance.

Cook's writings (e.g., 2001, 2003, 2009a) have been instrumental in orchestrating, with virtuosic command, the reshaping of a discipline with performance at its core by offering a much needed theoretical reformulation of key concepts-text, performance, and the musical work. Drawing on theatre and performance studies (e.g., Schechner, 1988, 2002), Cook re-theorized the musical textthe thing or object of analysis_-as a "script" that does not merely prescribe the act of performance but instead offers a set of possibilities, "choreographing a series of real-time, social interactions between players and a series of mutual acts of listening” (Cook, 2001, p. 5). Understanding scores as performative scripts entails uprooting old ways of thinking: performances are not deadpan reproductions of the score but culturally diverse practices prompted by scripts. Such a reorientation reinstates the act of performance in its rightful place; in the pragmatism of cultural life and the actions of all those partaking in performance. Without refuting the concept of the musical work, Cook integrated performance into it so that a work emerges as a more inclusive conglomerate, one that exists in the relation between the notated score and its performances as a "horizontal field of its performance instantiations” (e.g., Cook, 2001, pp. 5 and 7; 2003, pp. 207-8). This reformulation of the musical work achieves two aims. First, it redistributes the sites of meaning from a vertical hierarchy, running topdown from score to performance (also referred to as page to stage), to a horizontal and ontologically equivalent plane; second, it reconfigures the object of analytical/musicological discourse. Rather than seeking to find meaning intact in enduring products - compositions and scores-we may expect to uncover traces of meaning from a relational understanding of a potentially large number of ontologically equivalent but phenomenally different performance instantiations (Cook, 2001, p. 5). This theoretical orientation underpinned much of the empirical research undertaken at the Centre for the History and Analysis of Recorded Music (CHARM), especially comparative style analyses of recordings (e.g., Cook, 2009b; Leech-Wilkinson, 2007; Spiro et al., 2010). [2] By comparing hierarchical tempo scapes of operatic performances, Neumann too seeks a relational understanding of how interpretations of Puccini's Turandot have changed over time.

Although essentially espousing similar views to those outlined above about the relationship between the musical work and its performances, Neumann approaches the ontology of musical works from another perspective: the hermeneutic philosophy of Hans-Georg Gadamer (1989), specifically in relation to the dialogic character of tradition and the inter-subjectivity of (textual) interpretation, and the phenomenology of technology as expounded in Martin Heidegger's writings (1977). Neumann's theoretical exposition frames the practice of writing (notating music and also writing about music) as a form of technology, which etymologically denotes "the coming into appearance" and the "revealing of" objects, ideas or experiences. Understood in this way, scores, which are a form of technology or craft, "bring forth the work into being" through the act of performance. Neumann seeks to move away from the logocentric tradition of musical works as written texts, approaching them instead from, what he calls, an "opsicentric" perspective [3] that is more concerned with phenomenological aspects of the musical work as it "comes into being” in performance. The argument, however, could have been extended to embrace how the empirical tools and the analytical process also partake in this "opsicentric" approach; how these help reveal performance phenomena, such as subtle nuances in singers' interpretation of the musical-dramatic text, which might otherwise be less noticeable in the overall context of performance. This is implied by Neumann when he states in his introduction that "phenomenology, the relating of empirical observations of phenomena to each other [. . .] opens an empirical space to understand those practices and behaviours that constitute a performance, construct a tradition and practitioners' perceptions”. This “opening up of a space for understanding” strongly alludes to the interpreting subject becoming immersed in the dialogic fabric of tradition that Gadamer speaks of (1989). Rather than viewing the relationship between object (whatever that may be) and interpreter as binary, Gadamer treats the act of interpretation, and its inter-subjective mediation, as a single ontology. Interpretation is coextensive with understanding and, following Heidegger's Dasein, understanding [any work] is ontological—understanding is "being", it is the subject's mode of being historical by becoming implicated in an ongoing dialectical process of interpreting the past (Gadamer, 1989, p. 301). 


\section{TECHNOLOGICALLY MEDIATED OPERATIC OBJECTS FOR DISCOURSE}

Neumann's consideration of technology as the "revealing of experience" is particularly apt for the discussion of opera, but could potentially have been a bit more diversified and nuanced. In line with other forms of staged performance, opera embraces and mobilizes both old and new media: live and recorded voices and musical sounds, contemporary theatrical spaces and past locales, live onstage action and cinematically transmitted action onscreen, sung lyrics and projected text. This intensely vibrant mediatized culture has exciting consequences for our experience of opera which must acknowledge the means by which such experience and the discourses emanating from it are mediated. It calls for new ways to respond to the operatic past not only in terms of how it has been captured, such as in recordings, but also how it is relativized in the present through varied modes of study.

Although Neumann rightly points out that by-and-large "opera scholarship has relied on the study of scores, creating a lacuna of sound-based examinations", the omission of a more comprehensive review of the literature warrants further commentary. As Nicholas Till recounts, there was a time when the remit of opera studies was examining the formal aspects of operatic works represented by their scores. But the emergence of opera studies since the early 1990s has been accompanied by a decisive move away from formalist concerns and towards modes of study that not only investigate the historical context of operatic works but also the materiality of performance practices and events (Till, 2012a, pp. 1-2). Various chapters in The Cambridge Companion to Opera Studies (edited by Nicholas Till) deal with performance issues, and other more recent publications, such as The Business of Opera (Belina-Johnson \& Scott, 2015), focus on performance events for discussing the relevance, adaptation and longevity of operatic genres in today's society. Scholarly journals, such as the Cambridge Opera Journal or The Opera Quarterly have long attracted multidisciplinary approaches to the study of operatic performances as sounded phenomena and experiences in a mediatized culture (e.g., Senici, 2010).

Opera is an intermedial art form, created by the interaction between different media-music, poetry and theatre. These constituent elements must be temporally co-ordinated within the spaces of performance, which both channel and inflect the communicative processes of operatic events (live or recorded). A temporal hierarchy of operatic performance, as pursued empirically by Neumann, captures aspects of the intermedial interaction between performers, text, and stage. Although the authorial power traditionally ascribed to the musical text has privileged a discourse about singers' realization of the text, dramatic interpretation of operatic texts is more than that; it entails the production of a vocalgestural vocabulary, conditioned by specific cultural and historical environments, and the creation of a persona onstage. The operatic text is not just a pretext to performance, but necessitates the intermedial interaction between singers' bodies (and voices), the spatial and temporal parameters of performance, and the conditions of the theatrical construction of character. Intermedial negotiation creates a new species of "textuality" for performance (e.g., Morris, 2012, pp. 103-13; Till, 2012b, pp. 240-42) that undoubtedly impinges on the debate about the ontology of operatic works.

\section{OBJECTIFICATION OF PERFORMANCE IN EMPIRICAL RESEARCH}

The shift to a performance-based analytical discourse, I have outlined above, has not always been greeted with utopian optimism but also with resistance from certain scholars (for a succinct review, see Cook, 2009c, pp. 241-42). Empirical performance analysis has been subject to similar ideological attacks as traditional score-based analysis, due to the inevitable tendency to replace one object, the score, for another-the performance. The empirical methods employed to analyse performances (especially recordings) have often been criticized for objectifying musical phenomena, reducing them to textual representations abstracted from the act of performance, and reinventing a formalist discourse in a different guise; tempo graphs, time scapes, spectrographic visualizations and so on. Even Neumann acknowledges this when he states in the conclusions to his article that "scape plots emerge as a sort of text in and of themselves". In defence of empirical performance analysis, an obvious caveat of such criticisms is that these re-inscribe a "product over process" hierarchy by putting more emphasis on the empirical tools, although abstracted from context, rather than what the tools can do for us, what cultural work they can perform in the process of research. In other words, empirical performance analysis can be thought of as a performative act with the tools functioning as heuristics and not as a means to an end (e.g., Cook, 2006, 2009c; Cook \& Clarke, 2004).

John Rink cautions about the danger of "generating data for its own sake" that may result in a "disconnect between the concerns of the researchers and those of performers in general, which could limit the practical utility of the studies in question” (Rink, 2015, p. 128). Neumann's approach is, on the one hand, potentially susceptible to such criticisms since he attempts to reduce operatic 
performance, which is a multi-medium art form, into hierarchical tempo scapes. He acknowledges the limitations of reductionism by conceding that documenting other performance parameters, not just tempo, would yield a more holistic profile of operatic performance and its range of expressive possibilities. On the other hand, however, Neumann attempts to cross-validate empirical findings with ethnographic data (what performers say about what they do), giving his approach the kind of practical utility Rink advocates. Performances by their nature are temporally transient events that exist as the sonic traces, fragmentary memories and experiences they invoke. The need to account for some of these experiences in performers and listeners, by supplementing empirical analysis of recordings with ethnographic contextual evidence, has been voiced and documented by other scholars too (e.g., Fabian, 2015; Volioti, 2010, 2012). Although the epistemological impulse in Neumann's investigation runs predominantly from page to stage (i.e., tracing temporal interactions using the time scapes, and then validating hypotheses with singers' discourses from interviews), the reverse approach (i.e., identifying interpretative issues of interest and relevance to what performers need to do onstage and then use empirical analysis as a means to facilitate the process) would offer a welcome rapprochement to some of the problematic issues Rink mentions; the danger of becoming too distant from the practicalities of performance and its inextricably creative nature.

\section{ACKNOWLEDGEMENTS}

This article was copyedited by Scott Bannister and layout edited by Kelly Jakubowski.

\section{NOTES}

[1] Correspondence can be addressed to: Dr. Georgia Volioti, Department of Music and Media, University of Surrey, Guildford GU2 7XH, g.volioti@surrey.ac.uk

[2] For further details of research projects, see http://www.charm.rhul.ac.uk/index.html

[3] Derived from the Greek word opsis meaning appearance or phenomenal form.

\section{REFERENCES}

Barthes, R. (1990). Image, music, text (S. Heath, Trans.). New York: Noonday Press.

Belina-Johnson, A., \& Scott, D. (2015). The business of opera. London: Routledge.

Cook, N. (2001). Between process and product: Music and/as performance. Music Theory Online, 7(2). Retrieved from http://societymusictheory.org/mto/issues/mto.01.7.2/mto.01.7.2.cook.html

Cook, N. (2003). Music as performance. In M. Clayton, T. Herbert \& R. Middleton (Eds.), The cultural study of music: A critical introduction (pp. 204-14). New York: Routledge.

Cook, N. (2006). Border crossings: A commentary on Henkjan Honing’s "On the growing role of observation, formalization and experimental method in musicology”. Empirical Musicology Review, 1(1), 7-11. https://doi.org/10.18061/1811/24070

Cook, N. (2009a). Changing the musical object: Approaches to performance analysis. In Z. Blazekovic (Ed.), Music's intellectual history: Founders, followers and fads (pp. 775-90). New York: RILM.

Cook, N. (2009b). Squaring the circle: Phrase arching in recordings of Chopin's mazurkas. Musica Humana, 1, 5-28.

Cook, N. (2009c). Methods for analysing recordings. In N. Cook, E. Clarke, D. Leech-Wilkinson \& J. Rink (Eds.), The Cambridge companion to recorded music (pp. 221-45). Cambridge: Cambridge University Press. https://doi.org/10.1017/CCOL9780521865821.027

Cook, N., \& Clarke, E. (2004). Introduction: What is empirical musicology? In E. Clarke \& N. Cook (Eds.), Empirical musicology: Aims, methods, prospects (pp. 3-14). Oxford: Oxford University Press. https://doi.org/10.1093/acprof:oso/9780195167498.003.0001 
Cook, N., \& Everist, M. (1999). Rethinking music. Oxford: Oxford University Press.

Fabian, D. (2015). A musicology of performance: Theory and method based on Bach's solos for violin. Cambridge, UK: Open Book Publishers. https://doi.org/10.11647/OBP.0064

Gadamer, H-G. (1989). Truth and method (J. Weinsheimer \& D. G. Marshall, Trans. \& rev., 2nd ed.). London: Continuum.

Heidegger, M. (1977). The question concerning technology and other essays (W. Lovitt, Trans.). New York: Harper Perennial.

Kramer, L. (2002). Musical meaning: Toward a critical history. Berkeley: University of California Press.

Leech-Wilkinson, D. (2007). Sound and meaning in recordings of Schubert's Die junge Nonne. Musicae Scientiae, 11(2), 209-36. https://doi.org/10.1177/102986490701100204

Leppert, R., \& McClary, S. (1989). Music and society: The politics of composition, performance and reception. Cambridge: Cambridge University Press.

McClary, S. (1991). Feminine endings: Music, gender and sexuality. Minneapolis: University of Minnesota Press.

Morris, C. (2012). Too much music: The media of opera. In N. Till (Ed.), The Cambridge companion to opera studies (pp. 95-116). Cambridge: Cambridge University Press. https://doi.org/10.1017/CCO9781139024976.007

Rink, J. (2002). Musical performance: A guide to understanding. Cambridge: Cambridge University Press. https://doi.org/10.1017/CBO9780511811739

Rink, J. (2015). The (F)utility of performance analysis. In M. Doğantan-Dack (Ed.), Artistic practice as research in music: Theory, criticism, practice (pp. 127-47). New York: Routledge.

Schechner, R. (1988). Performance theory (revised 2nd ed.). New York: Routledge.

Schechner, R. (2002). Performance studies: An introduction. New York: Routledge.

Senici, E. (2010). Porn style? Space and time in live opera videos. The Opera Quarterly, 26(1), 63-80. https://doi.org/10.1093/oq/kbq010

Spiro, N., Gold, N., \& Rink, J. (2010). The form of performance: Analysing pattern distribution in select recordings of Chopin's mazurka op. 24 no. 2. Musicae Scientiae, 14(2), 23-55. https://doi.org/10.1177/102986491001400202

Till, N. (2012a). Introduction: Opera studies today. In N. Till (Ed.), The Cambridge companion to opera studies (pp. 1-22). Cambridge: Cambridge University Press. https://doi.org/10.1017/CCO9781139024976.001

Till, N. (2012b). The operatic work: Texts, performances, receptions and repertories. In N. Till (Ed.), The Cambridge companion to opera studies (pp. 225-53). Cambridge: Cambridge University Press. https://doi.org/10.1017/CCO9781139024976.014

Volioti, G. (2010). Playing with tradition: Weighing up similarity and the buoyancy of the game. Musicae Scientiae, 14(2), 85-114. https://doi.org/10.1177/102986491001400204

Volioti, G. (2012). Reinventing Grieg's folk modernism: An empirical investigation of the performance of the Slåtter op.72, no. 2. The Journal of Musicological Research, 31(4), 262-96. https://doi.org/10.1080/01411896.2013.720914 